\title{
Development and operation of a muon detection system under extremely high humidity environment for monitoring underground water table
}

\author{
H. K. M. Tanaka ${ }^{1}$ and A. Sannomiya ${ }^{2}$ \\ ${ }^{1}$ Earthquake Research Institute (ERI), University of Tokyo, Tokyo, Japan \\ ${ }^{2}$ Chigasaki Research Institute, J-POWER, Chigasaki, Kanagawa, Japan \\ Correspondence to: H. K. M. Tanaka (ht@riken.jp)
}

Received: 28 August 2012 - Published in Geosci. Instrum. Method. Data Syst. Discuss.: 10 September 2012 Revised: 26 December 2012 - Accepted: 4 January 2013 - Published: 23 January 2013

\begin{abstract}
In order to investigate the complex nature of landslides triggered by rainfall, dynamic muon radiography of the motion of the underground water table is planned in a drainage tunnel drilled underneath an estimated fault plane. However, the humidity inside the tunnel is almost $100 \%$. In order to suppress moisture effects, a scintillation counter with Cockcroft-Walton photomultipler tubes (CWMPT) was developed and tested at the observation site located in Shizuoka Prefecture, Japan. The counter was stably operated for 38 days without gain degrading. Based on the result, we constructed a muon detection system with $\mathrm{CW}$ PMTs at the same site and started operation runs. In this work, the data from borehole-based water gauge measurements of the underground water levels were analyzed and discussed. It was confirmed that the comparison between muon and borehole data would be useful.
\end{abstract}

\section{Introduction}

Rainfall induced landslides are usually shallow slips. Although the volume of slip mass is not very large in comparison to an earthquake, some of these landslides occur abruptly and travel a long distance at high speeds, and damage property and infrastructure. Some other landslides respond slowly to rainfall and move at much lower speeds, but they change landscapes for years. Preventing landslides can sometimes be as simple as maintaining proper drainage of water from the slopes by making, for example, a drain tunnel. However, up to this date, there has been no theoretical framework for understanding the relationship between hydrologic processes and the location, timing, rates, and magnitude of landslides.

Recently, theoretical models have been developed to predict how landslides are affected by topographic, geologic, and hydrologic conditions (Sidle, 1992; Montgomery and Dietrich, 1994; Dietrich et al., 1995; Wu and Sidle, 1995). In accordance with these models, rainfall influences groundwater only by modulating water table heights and groundwater flows parallel to the slope. These theories indicate that the water table heights in hill slopes respond to a rainfall event.

In order to assess the response of a rainfall event to the height of the water table in the area of landslides, we are planning to use dynamic muon radiography developed by Tanaka et al. (2011) to visualize the motion of the water table or saturation levels near the fault plane located in Shizuoka Prefecture, Japan. In the area, there are 8 vertical boreholes to measure the levels of underground water, but they only give one-dimensional information. Dynamic muon radiography showed a water flow in a mechanical fracture zone of a seismic fault in response to rainfall over varying periods of time (Tanaka et al., 2011). A similar type of muon radiography was proposed and conducted by George (1955) to determine the thickness of an overburden of a horizontal tunnel in the Snowy Mountains in Australia. He measured the muon flux inside and outside the tunnel to compare them to confirm that a reduction in the muon flux reflects the average density of the overburden. In this paper, the plan and the result of a test experiment of our newly developed device in a horizontal drain tunnel drilled right beneath the fault plane are described. We also have designed a photomultiplier tube 


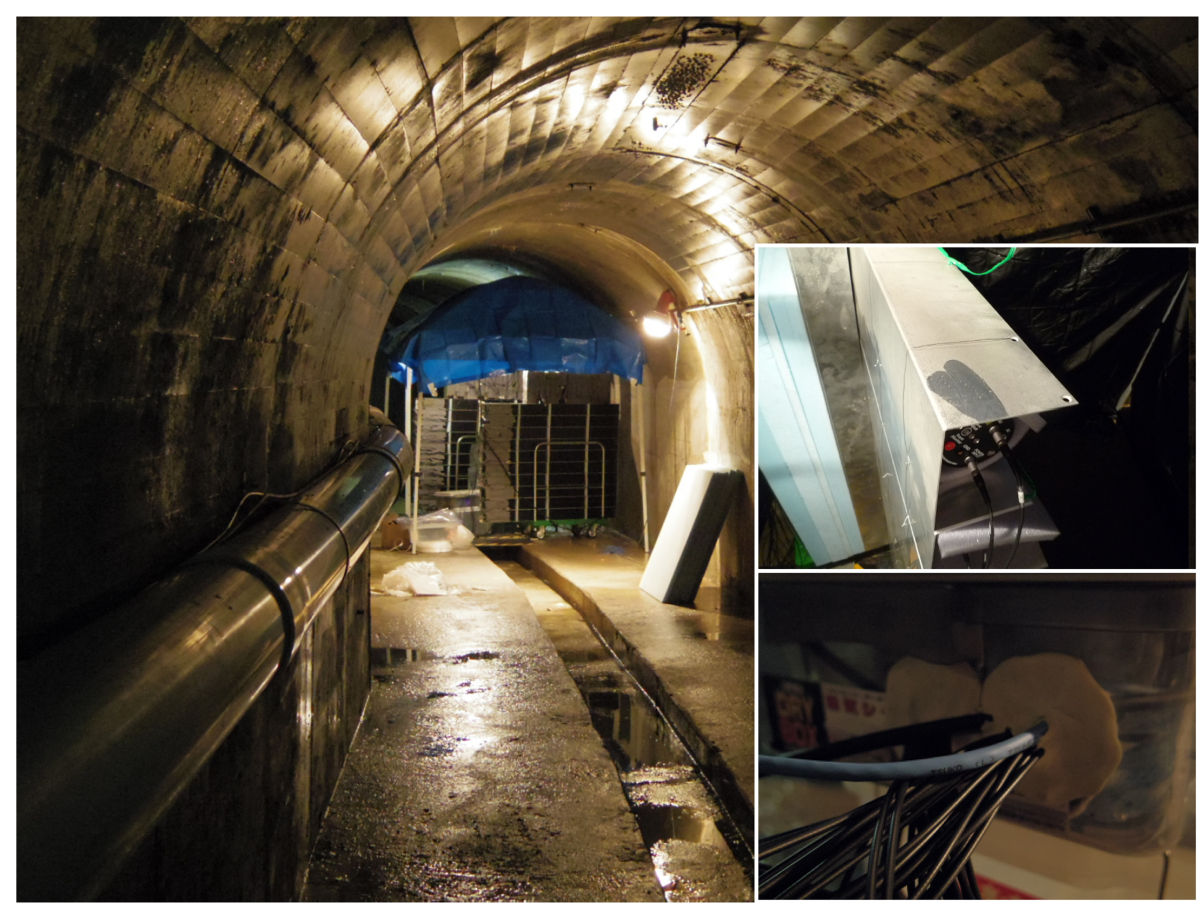

Fig. 1. Schematic of the detector design for the present measurement.

(PMT) for a muon radiography system to be used in an experiment to visualize a landslide fault. The detection system is placed in a horizontal tunnel right beneath the water table, where the humidity is $\sim 100 \%$ at all times.

\section{Muon radiography system under high humidity environment}

Our conventional muon detection system consists of plastic scintillator, PMTs, and a high voltage (HV) power supply that are separable to help the maintenance of the system. The $\mathrm{HV}$ power supply and long HV cable requirement is specific to our choice of PMT (Hamamatsu R7724) while there are other PMTs where compact HV supplies eliminate the need for long HV cables. The power supply usually does not need to provide a large amount of current, but it needs to produce thousands of volts needed to drive the dynodes of the PMTs. It has been confirmed that such a system works well even under relatively severe conditions over observation duration of a month. Tanaka et al. (2009a) conducted experiments in a vault at high altitudes of a mountain, and under a hot and humid semitropical environment where the humidity and the temperature constantly exceed $80 \%$ and $30^{\circ} \mathrm{C}$, respectively (Tanaka et al., 2009b). However, under an extremely high humidity environment (constantly $100 \%$ ), sufficient dielectric strength needs to be ensured for the high voltage connection of the high voltage electrical equipment. If the humidity is high, the moisture coats the surface of the material, providing a low-resistance path for electron flow. Furthermore, the condensation or moisture absorption on the insulation surface in the space of the high voltage connection causes the leakage current to increase, and sometimes the HV power supply and HV connections are seriously damaged.

Conventional techniques for applying a high voltage to PMTs utilizes a HV power supply, including a HV terminal which connects to a long electric wire for supplying high voltage electricity to PMTs. Several vendors provide small, encapsulated power supplies that meet the high voltage requirement, but long electric wires and the HV connections are still necessary.

One way to prevent such a current leakage is to soak the connectors and wires which high voltage is applied in transformer oil that has high dielectric strength. However, handling oil sometimes causes environmental problems in field measurements. An alternative way is enclosing the entire system in humid-proof housing with an appropriate air conditioning system. However, the size of the entire system usually spans more than $1 \times 1 \times 1 \mathrm{~m}^{3}$, and thus, this method is unrealistic. A schematic of the detector design is shown in Fig. 1. In this work, a Cockroft-Walton (CW) high-voltage PMT socket was designed and developed under collaboration between the University of Tokyo and Hamamatsu Photonics Japan in order to minimize the risk of a current leakage. A small current drives PMTs using a compact circuit board and can be totally self-enclosed. Such a configuration provides compact electrical equipment that can be operated even under high humidity environment. This type of circuit also has the advantage of dissipating much less power than 
(a)

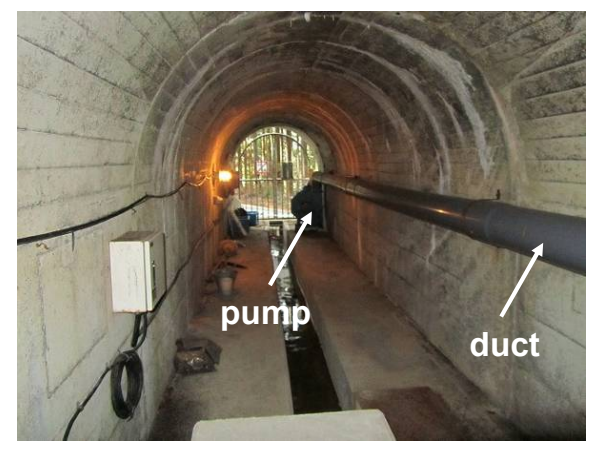

(b)

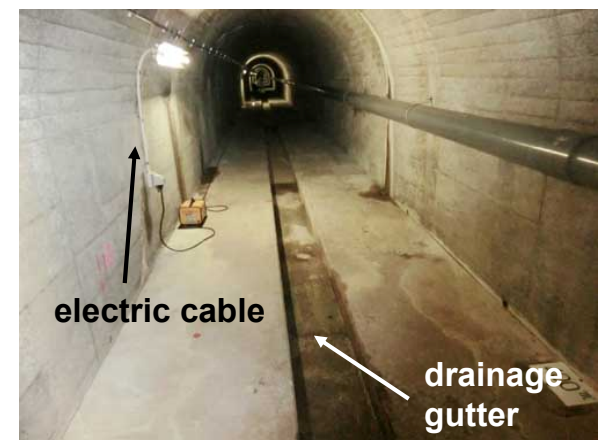

Fig. 2. Photograph of the infrastructure equipped in the drainage tunnel: (a) a turbofan exhaust duct, and (b) commercially available monophase $200 \mathrm{~V}$ electricity and the drainage gutter.

a resistive voltage divider. Minimal power dissipation is critical in the muon radiography detectors in which PMTs are densely packed.

\section{Experimental setup}

First, the geometrical structure of the drain tunnel was surveyed in order to obtain the precise position $(x, y, z)$ of the detection system in the tunnel. The directions (north, south, east, and west) were marked inside the tunnel. We also provided the tunnel with all the necessary equipment for muon radiography. Because the tunnel has a closed end, a turbofan exhaust duct was equipped as shown in Fig. 2a to provide air circulation and ventilation in the tunnel. Also, commercially available monophase $200 \mathrm{~V}$ electricity was converted to $100 \mathrm{~V}$ by a step down transformer and extended to a location of $397 \mathrm{~m}$ from the entrance of the tunnel where a scintillation counter that consists of a plastic scintillator strip and a CW-PMT was tested for an humidity endurance test (Fig. 2b). Figure 3 shows a cross sectional view of the hill slopes that we are planning to image. The blue line shows the estimated water table's head. The line was produced by connecting the underground water level measured in the borehole, and will be described more in detail in the Discussion section. W-\#\# in the figure indicates vertical boreholes for the underground water level measurements. Although there are 15 boreholes, the underground water levels are measured only at 8 boreholes. The underground water levels are measured with a water gauge (Tokyo Sokki Kenkyujo KW50CS). The water gauge is essentially a water pressure gauge that is placed under the ground water level. The measured value for the water pressure is used to calculate the altitude of the water level by using the information on the altitude of the location of the gauge. The water inflow is also measured in the tunnel. The data have been taken since June 1988, and were used for an analysis to see the general trend.

Also, in the same tunnel, a water inflow in a gutter (shown in Fig. 2b) is monitored. A triangular weir was made and

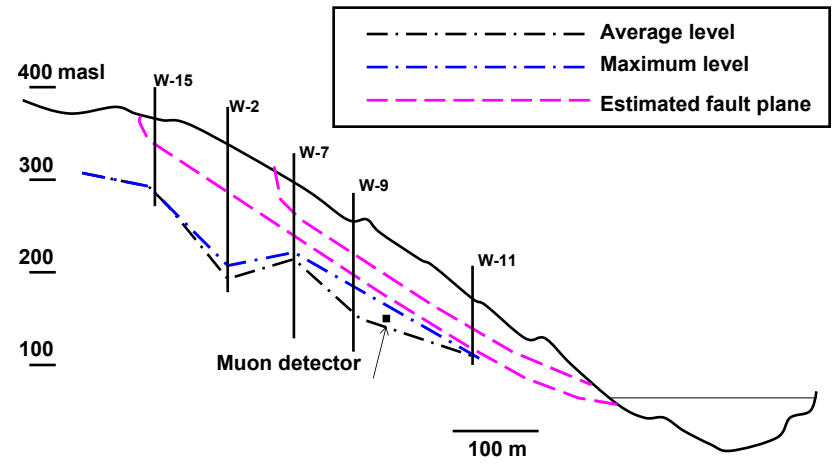

Fig. 3. Cross sectional view of the hill slope. The blue line shows the estimated water table's head. Two lines show the maximum and average water levels measured in the period between 1999 and 2010. The pink lines show the estimated fault lines. The underground water levels are measured at W-2, W-7 and W-9 boreholes.

the water levels are constantly measured by using a water pressure gauge (Tokyo Sokki Kenkyujo KW-1S). The water inflow is calculated from the water level and the water-level duration curve. The information on time-dependent changes in the underground water levels and the water inflow will be combined with the muon data to model the water table movements. The water inflow has been measured since 1990. The humidity, temperature, and output voltage from the step down transformer were also monitored at the observation point. Table 1 shows the altitudes, the depths, and the measurement depths of each borehole. Two pink broken lines in Fig. 3 show the estimated fault lines.

The objective of the CW-PMT is to provide reliable electrical equipment which can prevent the current leakage increase due to the condensation or moisture absorption on the high voltage insulation surface, and can be made compact. The Cockcroft-Walton circuit is basically a voltage multiplier which converts a low voltage level to a high voltage level (Greinacher, 1920; Cockcroft and Walton, 1932; Goebel, 1969). It comprises a multiplier ladder network of 
Table 1. Altitudes, depths, and measurement depths of the bore holes.

\begin{tabular}{lcrrrc}
\hline No. & Borehole & $\begin{array}{c}\text { Altitude } \\
(\mathrm{m})\end{array}$ & $\begin{array}{c}\text { Depth } \\
(\mathrm{m})\end{array}$ & $\begin{array}{c}\text { Pressure } \\
\text { gauge } \\
\text { depth } \\
(\mathrm{m})\end{array}$ & $\begin{array}{c}\text { Observation } \\
\text { time }\end{array}$ \\
\hline 2 & & & \multicolumn{1}{c}{} \\
\hline 7 & $\mathrm{~W}-2$ & 330.70 & 140.00 & 139.65 & March 1984 \\
9 & $\mathrm{~W}-7$ & 287.70 & 80.00 & 78.50 & March 1984 \\
\hline
\end{tabular}

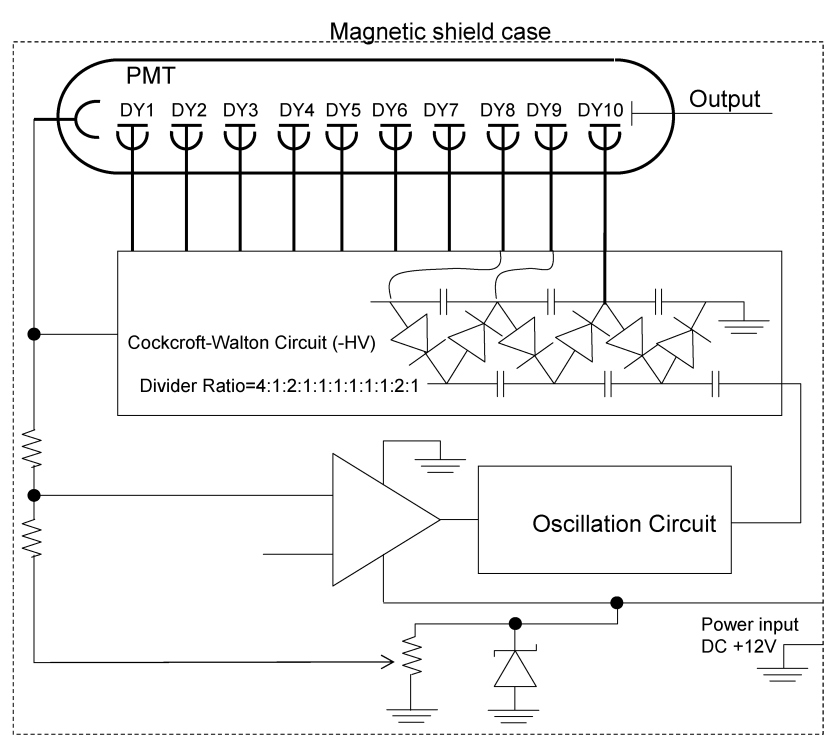

Fig. 4. Block diagram of the Cockcroft-Walton photomultiplier.

capacitors and diodes to generate high voltage. The two main components shown in the block diagram (Fig. 4) are the oscillator and the voltage multiplier. The oscillator section takes a DC input voltage (0 VDC to 12 VDC) and converts it to an AC sine-wave output. The AC sine-wave output amplitude was about 150 VAC peak-to-peak for a $5 \mathrm{VDC}$ input. The output of the oscillator section is input to the voltage multiplier section. The multiplier section is composed of ten stages. The operation of the multiplier is to effectively multiply the peak-to-peak AC input voltage by the number of stages and convert each output to a DC voltage. For example, with the oscillator output voltage set to $150 \mathrm{VAC}$, peak to peak, the voltage at the 1st stage of multiplication is $150 \mathrm{VDC}$. The voltage at the 10th stage of multiplication is 1500VDC. Stage voltages can be monitored with a standard digital multimeter. For example, the voltage across the $10 \mathrm{~K} \Omega$ resistor was a factor of $1 / 100000$ of the actual voltage being monitored. The outputs of the voltage multiplier were applied to a Hamamatsu R7724 PMT.
Table 2. Pulse output from the CW-PMT.

\begin{tabular}{lcccc}
\hline $\begin{array}{c}\text { Measurement } \\
\text { date }\end{array}$ & $\begin{array}{c}\text { Temperature } \\
\left({ }^{\circ} \mathrm{C}\right)\end{array}$ & $\begin{array}{c}\text { Humidity } \\
(\% \mathrm{RH})\end{array}$ & $\begin{array}{c}\text { Voltage } \\
\text { of the } \\
\text { power } \\
\text { supply } \\
(\mathrm{V})\end{array}$ & $\begin{array}{c}\text { PMT } \\
\text { pulse } \\
\text { height } \\
(\mathrm{V})\end{array}$ \\
\hline 27 Jan 2012 & 14.6 & 92 & 94.6 & $0.5-1.0$ \\
15 Feb 2012 & 14.4 & 93 & 93.6 & $0.5-1.0$ \\
5 Mar 2012 & 14.6 & 95 & 97.0 & $0.5-1.0$ \\
\hline
\end{tabular}

\section{Result of test measurements}

Table 2 shows the result of the operation of CW-PMT under conditions of extremely high humidity. The PMT was coupled with a plastic scintilator strip that is polished, wrapped in a layer of reflective Mylar, and covered with a lightshielding sheet. Figure 5 shows a photograph of a pulse output from the CW-PMT after 38 days have elapsed. The pulse was measured with an IWATSU Storagescope TS-81000. We did not see changes in pulse outputs between the beginning and after 38 days had elapsed. In the present measurement the humidity in the drain tunnel was constantly $\sim 100 \%$. In this work, it was confirmed that the CW-PMT can be operated stably for observation duration of more than one month even under conditions of extremely high humidity. This result makes muon radiography in the drain tunnel more realistic. It is possible for us to make a small housing to keep humidity constant to protect data-taking electronics.

Based on the result of this test measurement, we constructed a muon radiography measurement system in the drain tunnel (Fig. 6). The system contains scintillator strips arranged along the $x$ and $y$ coordinates like a lattice. The $x$ plane and $y$-plane detect the horizontal and vertical crossing position of a muon, respectively. The readout module processes signals from the detector part and generates a histogram for an angular resolution. The readout module is $35 \times 35 \times 160 \mathrm{~mm}$ in size and weighs $420 \mathrm{~g}$ and can be easily enclosed in a small humidity-proof box as shown in the inset of Fig. 6. A bag of silica gel is inserted in the box and is replaced every month. We anticipate that a stable long-term operation is possible with this system.

\section{Discussion}

The maximum and the average water levels measured in the period between 1999 and 2010 is shown in the cross sectional view of the hill slope (Fig. 3). The level of the water table is roughly below the estimated fault plane. The drain tunnel seems to function well. However, the water levels measured in boreholes of W-7 and W-9 increase gradually. At W-9, it increased $13 \mathrm{~m}$ since 1999 as shown in Fig. 7. 


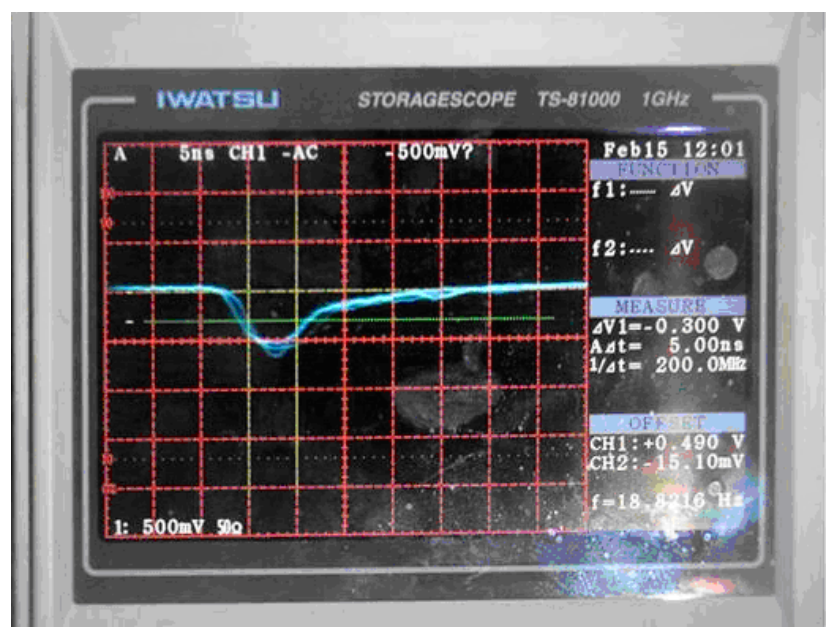

Fig. 5. Pulse output from the CW-PMT after 38 days have elapsed in the drainage tunnel.

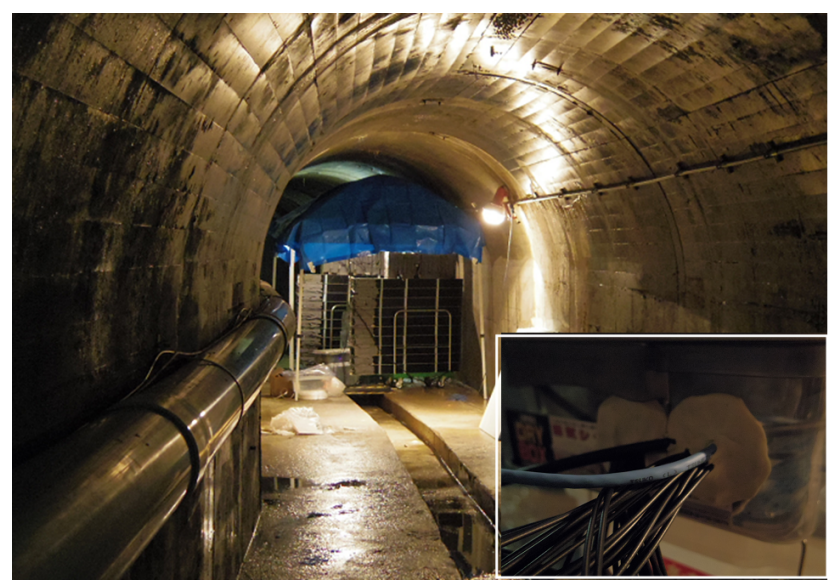

Fig. 6. Photograph of the muon radiography measurement system in the drain tunnel and a housing of the muon readout module (inset).

Iverson (1986) reports that in the case of the Minor Creek landslide (with thick soil and low hydraulic diffusivity) the water table's head response rises almost imperceptibly for a long time, even under rainfall of high intensity. This is consistent with the landslide type observed in this area. On the other hand, the water level measured at W-9 tends to change widely after the rainfall event and reached $187 \mathrm{~m}$ a.s.l. on 15 July 2007 as shown in Fig. 7. Such a rapid growth of the water table head in abrupt response to intense rainfall can cause catastrophic landslides. However, we cannot simply conclude that the catastrophic landslide will occur at W9 site in the near future because borehole characterization is not sufficient to characterize the subsurface hydrological conditions within the landslide mass, and the information on depth and lateral continuity of the sliding surface (Mondal et al., 2008). Moreover, no changes in the water level were found at W-2 site between 1999 and 2011. Obviously, there

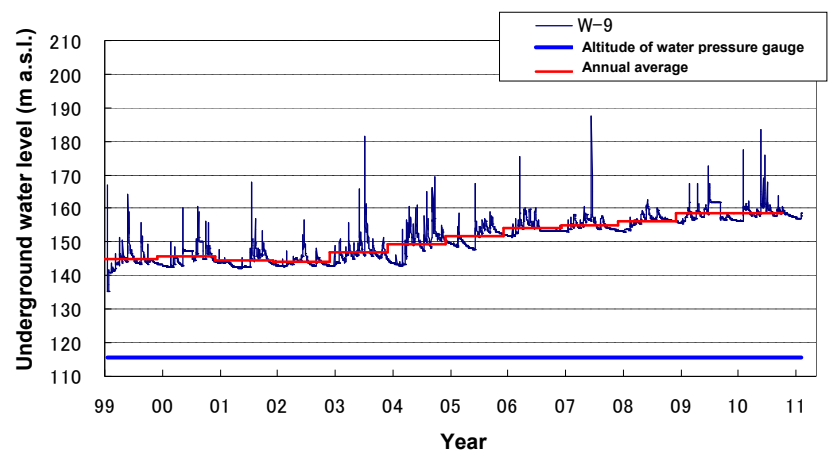

Fig. 7. The water levels measured at W-9 borehole in the period between 1999 and 2010.

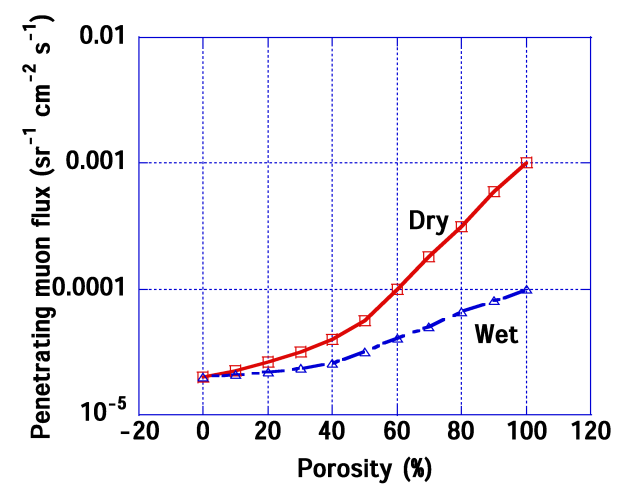

Fig. 8. Penetrating muon flux before and after saturating the porous rock with water.

is a limitation for estimating the underground water motion by borehole observations. Non-destructive muon radiography can offer an opportunity to investigate landslides by providing three dimensional water saturation levels which can be imaged in real time.

As shown in Fig. 7, the underground water level can rise by $20-30 \mathrm{~m}$. It is known that such an event happens when over $100 \mathrm{~mm} \mathrm{day}^{-1}$ of rain is observed in the local area, and completely saturates the porous media above the water table. Under such conditions, the average density of the surrounding rocks drastically increases. Figure 8 compares the penetrating muon flux before and after saturating the porous rock for different porosity. The rock thickness was assumed to be $200 \mathrm{~m}$, which is corresponding to a typical path length of the rock overburden at the observation site. The density of the non-porous rock was assumed to be $2.5 \mathrm{~g} \mathrm{cc}^{-1}$. As shown in Fig. 8 , as the rock porosity increases, the muon penetrating flux decreases. If the rock porosity is $10 \%$, the penetrating flux is reduced by $10 \%$ when it is saturated with water. On the other hand, 200-1000 muons are collected per day with a $1-\mathrm{m}^{2}$ detector. Therefore, such reduction can be measured by our present observation system in a relatively short observation time. 
Based on the result of the borehole-based water level measurement, the duration of the high water level is not so long: the water level changes sometimes occur within a duration of one day. In order to obtain a high resolution image, stroboscopic muography might be usable (Tanaka, 2012). Although the natural cosmic-ray muon flux limits the required image integration time to achieve acceptable number of muons, the low muon statistics in dynamic muon radiography can be substantially improved if the process under study is repetitional by integrating a number of frames to form one image which has sufficient statistics, without degrading spatial resolution of the image. In order to distinguish the watersaturated from the non-saturated layer with muon radiography, it is also important for us take background data when the climate is relatively dry or when the underground water level is stable and low.

\section{Conclusions}

In the present test measurement, we confirmed that the muon detection system using CW-PMT combined with a Cockcroft-Walton circuit has the following advantages for muon radiography in a drain tunnel: (a) a stable long-term operation under extremely high humidity encironment, and (b) a power effective operation. By analyzing the data collected by the borehole water-level measurements, we found that the watertable's head response to the rainfall event as well as the long-term trends of the water level. However, the complex nature of the landslides triggered by rainfall necessitates the need for investigating their characteristics in a more detailed manner. We anticipate that dynamic muon radiography will provide more comprehensive information

Acknowledgements. This work is a part of a collaborative research between the University of Tokyo and Electric Power Development Company (J-POWER). The manuscript greatly benefited from careful review by Justin Albert and anonymous reviewers.

Edited by: J. Albert

\section{References}

Cockcroft, J. D. and Walton, E. T.: Experiments with high velocity positive ions (II) - The disintegration of elements by high velocity protons, P. Roy. Soc. Lond. A, 137, 229-242, 1932.

Dietrich, W. E., Reiss, R., Hsu, M.-L., and Montgomery, D. R.: A process-based model for colluvial soil depth and shallow landsliding using digital elevation data, Hydrol. Process., 9, 383-400, 1995.

George, E. P.: Cosmic rays measure overburden of tunnel, Commonwealth Engineer, Tait, Melbourne, 455-457, 1955.

Goebel, W.: A new modification of the cockcroft-walton voltage multiplier circuit, Nucl. Instrum. Meth., 67, 331-336, 1969.

Greinacher, N.: High Voltage DC Generator, Bull. Schweiz. Elek. Ver., 11, 59, 1920.

Iverson, R. M.: Dynamics of slow landslides: A theory for timedependent behavior, in: Hillslope Processes, edited by: Abrahams, A. D., Allen and Unwin, Winchester, Mass., 297-317,1986.

Mondal, S. K., Sastry, R. G., Pachauri, A. K., and Gautam, P. K.: High resolution $2 \mathrm{D}$ electrical resistivity tomography to characterize active Naitwar Bazar landslide, Garhwal Himalaya, India, Current Sci., 94, 871-875, 2008.

Montgomery, D. R. and Dietrich, W. E.: A physically based model for the topographic control on shallow landsliding, Water Resour. Res., 30, 1153-1171, 1994.

Sidle, R. C.: A theoretical model of the effects of timber harvesting on slope stability, Water Resour. Res., 28, 1897-1910, 1992.

Tanaka, H. K. M.: Development of stroboscopic muography, Geosci. Instrum. Method. Data Syst. Discuss., 2, 671-684, doi:10.5194/gid-2-671-2012, 2012.

Tanaka, H. K. M., Uchida, T., Tanaka, M., Takeo, M., Oikawa, J., Ohminato, T., Aoki, Y., Koyama, E., and Tsuji, H.: Detecting a mass change inside a volcano by cosmic-ray muon radiography (muography): First results from measurements at Asama volcano, Japan, Geophys. Res. Lett., 36, L17302, doi:10.1029/2009GL039448, 2009a.

Tanaka, H. K. M., Uchida, T., Tanaka, M., Shinohara, H., and Taira, H.: Cosmic-ray muon imaging of magma in a conduit: Degassing process of Satsuma-Iwojima Volcano, Japan, Geophys. Res. Lett., 36, L01304, doi:10.1029/2008GL036451, 2009b.

Tanaka, H. K. M., Miyajima, H., Kusagaya, T., Taketa, A., Uchida, T., and Tanaka, M.: Cosmic muon imaging of hidden seismic fault zones: Rainwater permeation into the mechanical fractured zones in Itoigawa-Shizuoka Tectonic Line, Japan, Earth Planet. Sc. Lett., 306, 156-162, 2011.

Wu, W. and Sidle, R. C.: A distributed slope stability model for steep forested basins, Water Resour. Res., 31, 2097-2110, 1995. 